Proceedings of the 2009 Winter Simulation Conference

M. D. Rossetti, R. R. Hill, B. Johansson, A. Dunkin, and R. G. Ingalls, eds.

\title{
CONTROLLING DIRECT-TO-CONSUMER ADVERTISING, PROFESSIONAL PROMOTION AND THE PRICE OF PHARMACEUTICAL DRUGS
}

\author{
George W. Pasdirtz \\ University of Wisconsin \\ Madison, WI 53706, USA
}

\begin{abstract}
Direct-to-consumer (DTC) advertising is the most visible and controversial part of contact between patients and the pharmaceutical manufacturers but it is only part of the current promotional mix. Advertising in medical journals, detailing (direct sales calls on physicians) and distribution of free samples are all used along with DTC advertising to induce product demand. In this paper, I exploit a new data set on pharmaceutical promotion (Donohue, Cevasco, and Rosenthal 2007) to estimate two state space models: one model explains the dynamics of pharmaceutical promotion and another investigates the impact of pharmaceutical promotion on the market for pharmaceutical products. Simulation results suggest that limitations on professional detailing and free samples (not DTC advertising) could reduce cyclical instability of pharmaceutical promotion. However, the pharmaceutical market does not behave as a competitive market, that is, while promotion increases sales, prices have no statistically significant negative feedback effect on sales. As a result, promotional controls will reduce sales but not prices. Market failure suggests a range of interventions that might be applied to pharmaceutical pricing.
\end{abstract}

\section{INTRODUCTION}

Expenditures on pharmaceuticals are thought to be one of the most important cost-drivers in the US health care system (Anderson, Reinhardt, Hussey, and Petrosyan 2003, Pasdirtz 2007). Starting in the 1980's, the percent of US National Health Expenditure (NHE) devoted to pharmaceutical drugs reversed direction after a period of decline and began rapidly increasing. In the late 1980's, pharmaceutical manufactures started direct-to-consumer (DTC) advertising of drugs and, coincidentally, expenditures on pharmaceutical drugs accelerated. The FDA regulates DTC advertisements and, in 2003, released results of a third survey of physicians prescription practices. Most physicians seem to agree that DTC advertising has led patients to ask more thoughtful questions, involved patients more directly in their care, and gives physicians the opportunity to provide more detailed information. Few physicians felt pressured to prescribe a particular advertised drug (Lewis 2003). Yet, adverse side effects from heavily advertised drugs such as Vioxx (rofecoxib) and limits on FDA oversight of DTC advertising (GAO 2002) have led to increased concerns over DTC advertising (Donohue, Cevasco, and Rosenthal 2007, Sweet 2005).

From 1996 to 2005, DTC advertising increased by 330\% while total pharmaceutical promotion grew by 262\% (Donohue, Cevasco, and Rosenthal 2007) and drug sales as a percentage of NHE increased by about $160 \%$. All forms of pharmaceutical advertising have raised policy questions about the impact of promotion both on consumer demand for pharmaceuticals and on the prices of pharmaceuticals, the later of which rose $140 \%$ over the same period. In this paper, I use data covering total spending on pharmaceutical promotion from 1996-2005 (see Appendix A for data sources) to model expenditures on DTC advertising, professional promotion (detailing and journal advertising), distribution of free samples, and the Producer Price Index (PPI) for pharmaceuticals. I also model the overall pharmaceutical market as a partial-equilibrium system. Simulation results suggest a role for limiting professional detailing and free samples (but not DTC advertising) to reduce instability in drug promotion and limit conflicts of interest (IOM 2009). However, there will be little impact on prices due to imperfections in the market for pharmaceutical drugs.

This paper is organized as follows. Section 2 applies the theory of monopolistic competition to describe the motivation for pharmaceutical promotion and then applies price index theory to explain how pharmaceutical promotion can increase aggregate pharmaceutical prices. Section 3 describes state space methodology, the database used for the statistical analysis 


\section{Pasdirtz}

and how macro-simulation differs from micro-simulation of health care policy. Section 4 describes the results of estimating and simulating the model. The results suggest a policy role for controlling free samples and promotional detailing but does not find a statistically significant effect of pharmaceutical promotion on aggregate pharmaceutical prices. Section 5 discusses the policy results and proposals for restructuring the pharmaceutical industry to control prices.

\section{THEORY}

This section presents the theory of monopolistic competition to explain the motivation for pharmaceutical promotion and the unobservable variables that enter into decisions about sales expenditures and price setting. Price index theory is also presented to explain how pharmaceutical promotion can have a positive impact on aggregate pharmaceutical prices.

In partial-equilibrium monopolistic competition, there are a number of firms with differentiated products and limited entry. Firms will face a downward sloping demand curve (the less differentiated the products, the steeper the slope of the curve). If more firms were able to enter the industry, the individual firm's demand curve would shift downward toward equating marginal cost with marginal revenue at a lower price. In monopolistic competition, firms can control the industry's demand curve either by changing the slope of the curve or by shifting the demand curve to the right (upward) using promotion or innovation. In the pharmaceutical industry, entry is limited given capital costs, economies of scale, patent protection and the small number of major pharmaceutical manufacturers. Marginal costs are almost constant. The added production cost of one pill (for example) is so small that different dosages are often priced the same (Berndt 2002). Fixed costs are large due to research and development (R\&D) (Grabowski and Vernon 2000). Advertising is not a fixed cost since it declines dramatically when patent protection expires and the monopoly is broken. In a monopolistic industry "... the appropriate level of advertising will depend very heavily on the special characteristics of the product ..." (Dorfman and Steiner 1954) and might best be viewed as an investment in "goodwill" that depreciates over time (Nerlove and Arrow 1962). However, promotion will still be used as long as marginal revenue exceeds promotional costs and innovation can create new drugs and imitators ("me-too" drugs e.g., Viagra, Cialis and Levitra) (Grabowski and Vernon 2000).

The purpose of DTC and other forms of advertising is to build and maintain demand for and prices of drugs even after patent expiration. DTC advertising is presumed to influence consumers to ask their physicians to prescribe the drug and then insist on brand loyalty over time. However, there is a feedback effect from physicians to patients in which patient symptoms and appropriateness of the advertised drug are discussed with the ultimate decision being reserved for the physician as principal agent. The agency problem generated by physician gatekeepers suggests that professional advertising and detailing might be more important than DTC advertising. Professional advertising began when the medical profession dominated patient contacts while DTC advertising evolved along with changes in the corporate practice of medicine (Robinson 1999). Physicians and nurse practitioners, however, are still at the center of the decision process.

The effect of pharmaceutical promotion on prices is more difficult to predict since prices may largely reflect unobservable perceptions of product value held by consumers, physicians and payers (Berndt 2002). Empirical evidence is mixed on whether or not advertising reduces the price elasticity of demand (Gönül, Carter, Petrova, and Srinivasan 2001, Rizzo 1999). From an accounting perspective, development costs may be a more significant determinant of pharmaceutical prices. Pharmaceutical promotion costs were $18.2 \%$ of sales in 2005 while DTC advertising was only $2.6 \%$ of sales. In 2002, $\$ 22,997$ million was spent on total promotional spending (Donohue, Cevasco, and Rosenthal 2007) while it is estimated that between 1989 and 2002 it costs $\$ 802$ million in 2000 dollars (Demasi, Hansen, and Grabowski 2003) to develop the average drug. The widely quoted $\$ 802$ million figure is controversial and may be as high as $\$ 2$ billion for some drugs (Adams and Brantner 2006). The results presented in this paper do not depend on how the prices were determined and whether the prices were or were not excessive. Macro analysis simply assumes that as long as one equivalent drug is more expensive than another, other things being equal, advertising that increases the market share of the more expensive drug will increase the aggregate price level. Even if pharmaceutical promotion is a small part of total cost, anything that increases demand for a more expensive drug can have a positive impact on the aggregate price level.

Price index theory (Diewert 1993, Triplett 1992) explains how such aggregation effects can increase the overall price level. Consider the situation where there is initially a unique, patented pharmaceutical selling at price $p$ and sales $q$. At time one, the unilateral price index is $p_{1}=1=\left(p_{1} q_{1}\right) /\left(p_{1} q_{1}\right)$. At time two, the drug runs out of patent protection and a generic drug is introduced creating a bilateral index for this class of drug. If the generic drug sells for $1 / \beta$ times the price of the patented drug and the generic drug entirely replaces the patented drug with no change in sales, the aggregate price index drops to $p_{2}=\left(p_{1} q_{1}\right) / \beta\left(p_{1} q_{1}\right)=1 / \beta$. On the other hand, if pharmaceutical promotion maintains sales of the higher priced patented drug at level $[1>\alpha>0]$, then the aggregate pharmaceutical price index will be higher $p_{2}=\left[p_{1} \alpha q_{1}+\left(p_{1} / \beta\right)(1-\alpha) q_{1}\right] / p_{1} q_{1}=\alpha+(1-\alpha) / \beta>1 / \beta$ iff $\alpha \neq 0$. If pharmaceutical promotion increases sales of the patented drug, aggregate prices would be further increased. In this way, promotion can increase aggregate pharmaceutical 


\section{Pasdirtz}

prices even if promotion has a negligible impact on the cost of producing a pharmaceutical. Things are of course more complicated at the macro level with multilateral price indexes (more patented and generic products with different sales and prices that all change from period to period) and statistical analysis is required to determine effects. However, economic theory would argue that unless pharmaceutical promotion had macro effects, it would not be rational to engage in the activity. These theoretical results have been confirmed by empirical analysis (Grabowski and Vernon 1992) and interpreted in terms of market segmentation with the market for patented medicines being price insensitive (Frank and Salkever 1992).

\section{METHOD}

This section describes (1) the data set used to estimate the state space models, (2) the difference between macro- and micro-simulation approaches to understanding health care policy issues and (3) how state space methodology can be used to explain the pharmaceutical sales system and the dynamics of the market for pharmaceutical drugs.

The promotional data were available from 1996-2005 (Donohue, Cevasco, and Rosenthal 2007). The data were drawn from five basic sources: IMS Health, PhRMA's annual reports, TNS Media, Verispan, the US Bureau of Labor Statistics, and the Centers for Medicare \& Medicaid Services. The data sources have limitations. For example, Verispan tracks the 10 therapeutic drug classes that had the highest US sales, tracking DTC advertising, detailing, advertising in professional journals, meetings and educational events for physicians and online pharmaceutical promotion to physicians. The 20 drugs with the highest spending made up 54.4\% of total industry spending on advertising in 2005. Data from IMS Health and TNS media are based on sampling and panel data. TNS Media data are representative of major media markets. PhRMA collects data only from its members. Although not complete, there is no reason to think that the data are biased or that the time trends of expenditure categories would be different with more completeness. The data sources are discussed further in Appendix A.

From the standpoint of systems theory, there is little formal difference between micro- and macro-simulation (Rozenblit and Zeigler 1993, Zeigler and Vahie 1993). Each approach is interested in understanding the effects of input variables on states of the system. At the operational level, however, micro- and macro-simulation differ in how the models are constrained (Kalman 1980): (1) Micro-simulations are typically constrained by direct observation of the system being modeled. A hospital emergency room, for example, can be observed and modeled. At the macro-level, direct observation is not readily available. The promotional activities of every firm in the pharmaceutical industry, for example, cannot be directly observed. (2) Micro-simulations can also be constrained by assumptions about the optimizing behavior of objects within the simulation. Managers, doctors, nurses, technicians and patients can be assumed to be utility maximizers and the assumption can be used to model their behavior or at least suggest how the system might function if participants did optimize their utility. Although macro-simulations have been based on assumptions about representative agent optimizing behavior, the assumptions cannot be verified (Hartley 1996, Kirman 1992). (3) Because the system and its participants cannot be observed, macro-simulation must rely on either calibration or statistical analysis. (a) When calibration is used, model parameters are computed in a base year. Calibration requires that the parameters being calibrated are actual parameters within the physical system, an assumption that may be difficult to validate (a good example would be parameters of the utility function). For highly non-linear systems, small changes in calibrated parameters can produce large and uncontrolled changes in the simulation (Kalman 1980). (b) Statistical analysis is preferable where data exist. Estimating individual equations sequentially is affected by specification error (incorrect functional form, unobserved variables, irrelevant variables, simultaneity bias and measurement error) and, in the simulation context, the single equations taken together may not behave in a realistic manner. State-space approaches address these issues both for macro- and for micro-simulations.

Testing economic models of pharmaceutical advertising is complicated by many unobservable variables (goodwill, profit forecasts, expectations about competitor strategies (Lim and Ong 1989), assumptions about government policy, expectations of patients, providers, and payers, etc.). To allow for the effect of internal, unobservable variables, models were estimated with state space techniques. To use state space models, decisions have to be made about the collection of output variables that describe the system and the collection of input variables, if any, that are assumed to be outside the system. The output variables are connected to each other and to the input variables by the unobservable, internal state variables. If all the system states are observable and reachable (observability and reachability are attributes of certain matrices in state space models) then the system is controllable (Rohrs, Melsa, and Schultz 1993). The state space models presented below are controllable as is the overall US health care system (Pasdirtz 2007). State space models provide a minimal realization, that is, the smallest canonical model that can explain the time path of the output variables (Kalman 1980). Conventional regression approaches that predict, for example, prices from R\&D expenditure or DTC advertising (Giaccotto, Santerre, and Vernon 2005), must be isomorphic with state space models (Kalman 1980). For this paper, I will look at two systems: (1) the drug promotional 


\section{Pasdirtz}

system that includes mass-market and professional promotion and (2) the market for pharmaceutical products. More details of the estimation algorithms are provided in Appendix C.

The two systems models are analyzed below using impulse-response analysis. The initial conditions of the state variables are set to zero and then the initial condition of each input variable is set to unity, simulating a one-standard deviation shock. The impulse response is applied to each input variable and the system is simulated (solved numerically) to produce ten-period time plots. The estimation of time series models and methods of analysis (to include impulse-response analysis) are controversial (Cooley and Leroy 1985, Kalman 1980, Moore 1985, Lutkepohl 2006, Runkle 1987, Sims 1986, Stoll 1982). Systems theory, state space models and nonparametric statistical techniques address some of the issues in the literature (unobserved variables, multicolinearity, cointegration, simultaneous causality, measurement error and violation of assumptions) but not all. Due to space limitations, the coefficient estimates and the detailed results of testing model assumptions (homogeneity of variance, unit roots, normality, residual chaos, nonlinearity, cointegration and stationarity), are not presented below. When assumptions were violated, nonparametric bootstrap tests were constructed for the models (Clements and Taylor 2001, Freedman 1981, Freedman and Peters 1984, Runkle 1987, Stoffer and Wall 1991). To test the overall model, the largest characteristic root, $\lambda_{1}=E^{-1} H$, was bootstrapped using $E=Y^{\prime} Y-(X B)^{\prime} X B$ and $H=(X B)^{\prime} X B$ from the AR coefficients (Morrison 1967).

\section{RESULTS}

This section describes the results of estimating and simulating the two state space models.

The initial construction of the systems models was checked using Granger causality testing (Granger 1969). Granger causality testing estimates all bivariate dynamic relationships in the system. It assumes that if the bivariate relationship is not significant then one variable cannot be said to dynamically cause another. Granger causality testing suffers from all the problems mentioned above but does provide a point of comparison for the system model results. In some cases, Granger causality testing confirmed results from the systems models. For example, drug prices Granger-cause expenditure for drugs $(p \leq 0.04)$, but causality does not run from expenditure to prices. The result is further confirmed by examining coefficients within the systems models (Blanchard and Quah 1993, Blanchard and Quah 1989). Prices have little contemporaneous effect on expenditure but over time increasing expenditure only gradually reduces prices. In other case, Granger causality testing was misleading. For example, DTC advertising Granger-caused increases in drug prices $(p \leq 0.01)$, a result that was not confirmed by the systems model.

State variables for the drug promotion model were constructed from standardized output variables using the weights presented in Appendix B. The first state variable described overall growth in promotional activity, the second state variable was heavily weighted on promotional journal advertising and the third state variable was heavily weighted on free samples. Experimentation with the model found that excluding the third state variable (free samples and detailing) produced model stationarity (the largest characteristic root of the system matrix was 0.985). A bootstrap test of the characteristic roots, however, indicated that a unit root cannot be ruled out in probability. To preserve stationarity, the third state variable was used as an input policy variable. All states of the drug promotion model were observable and reachable.

Some of the output variables in the drug promotion model failed the residual level-stationarity test at the $p \leq 0.01$ level and there were not enough observations to test homogeneity of variance. Given the small number of observations (1996-2005), nonparametric tests were used. The overall test statistic for the drug promotion model, $\lambda_{1}$, was significant at the $p \leq 0.04$ level. Figure 1 shows the short-run impact of increases in free samples and detailing (the third state variable) on the drug promotion system. DTC advertising, promotional detailing, free-samples, total promotion and total sales all decline in response to an increase in the third state variable while promotional journal advertising increases. I would interpret this result to describe the initial phases of product introduction where the primary focus is on physician awareness through initial free samples, detailing and then follow-up in the professional journals.

The next model estimated the effect of promotional expenditure on the pharmaceutical market. The model was based on the Blanchard-Quah approach (Blanchard and Quah 1993, Blanchard and Quah 1989) with the addition of the pharmaceutical promotion state variables as inputs. For this model, the largest characteristic root, $\lambda_{1}$, was not significant. Granger causality testing indicated that while pharmaceutical promotion had an impact on pharmaceutical sales, pharmaceutical sales did not have an impact on pharmaceutical prices. Since the lack of statistical significance for the drug market model may have been a function of the small sample size, the impulse response to the pharmaceutical promotion state variables is presented in Figure 2 even though it is not statistically significant. Increases in overall promotional expenditure (row 1 of Figure 2) increases NHE while increases in promotional journal advertising and free samples (rows 2 and 3, respectively) decreased pharmaceutical expenditures. The price impacts, although not statistically significant, suggest that initial promotional expenditure results in mild price increases over the next few years. 

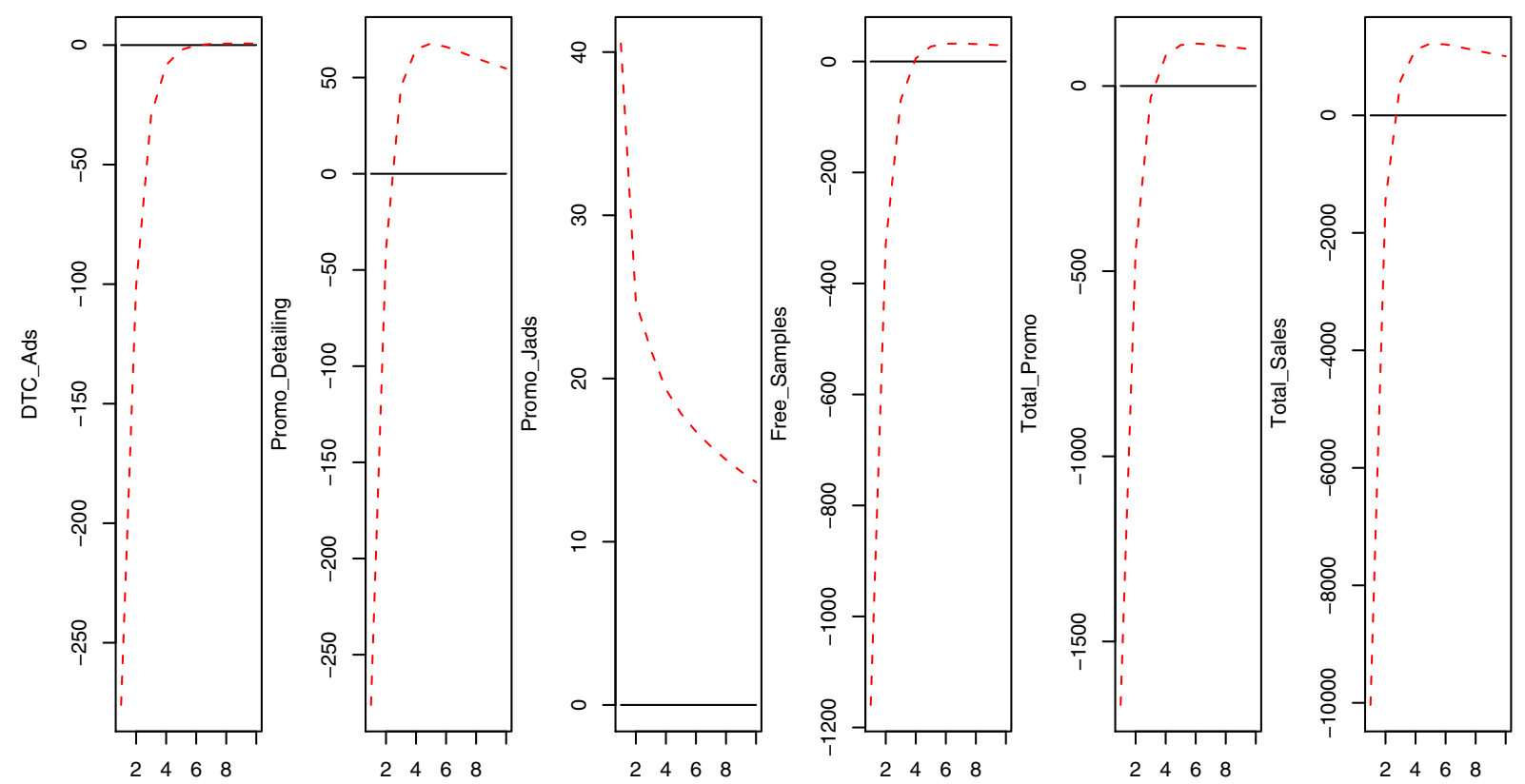

Figure 1: Pharmaceutical Sales Model Impulse Response to Free Samples and Detailing (see Appendix B for definition of terms)

Focusing only on sales, there are significant impacts of the first two drug promotion state variables on sales $(p \leq 0.01)$. Free samples and detailing, however, did not have a significant direct impact on sales. In Figure 3, drug expenditures were (1) increased by increases in overall promotional expenditure (the first row), (2) decreased by journal advertising (the second row) and (3) decreased by free samples and detailing, the last row. Both forms of professional promotion, however, increased sales after a few years and maintained sales for many years afterward.

\section{Discussion}

This section discusses the results, the limitations of this study and its application to the broader issue of restructuring the pharmaceutical industry.

The results suggest that there are some policy benefits to controlling detailing and free samples. Best practices currently place some restrictions on contacts between pharmaceutical sales representatives and physicians (Annonymous 2008, IOM 2009), but these restrictions could be strengthened. For example, many specialists have multiple affiliations at both hospitals and clinics. While a hospital might restrict detailing and free samples, the clinic might not. Both should restrict physician contact with pharmaceutical sales representatives to stabilize the current promotional system. On the other hand, DTC advertising by itself does not have a major impact on shifting demand for pharmaceuticals.

My conclusions in this paper are that: (1) DTC advertising is not the primary driver for pharmaceutical promotion. Rather, the introduction of new compounds is followed by an increase in free samples, detailing and journal advertising followed by acceleration in general promotional activities to include DTC advertising. (2) The increase in DTC advertising, detailing and journal advertising peaks about three years after a product innovation. Any policy placing a moratorium on DTC advertising should acknowledge the dynamic time path of pharmaceutical promotion. For example, Bristol-Myers Squib announced a voluntary moratorium on DTC advertising for one year after FDA approval of a new compound. The moratorium, however, would not have had a practical impact given the observed impulse responses presented above. (3) Pharmaceutical promotion, to include DTC advertising, is not the primary driver of increased prices for pharmaceutical products since promotion primarily increases sales. Whether increased sales leads to overuse or alleviates underuse is an area for future research (Donohue 2006, Sweet 2005). (4) Instability in the drug promotion process could be reduced by eliminating free samples and detailing. Other approaches could be found to provide free drugs to patients who cannot 


\section{Pasdirtz}
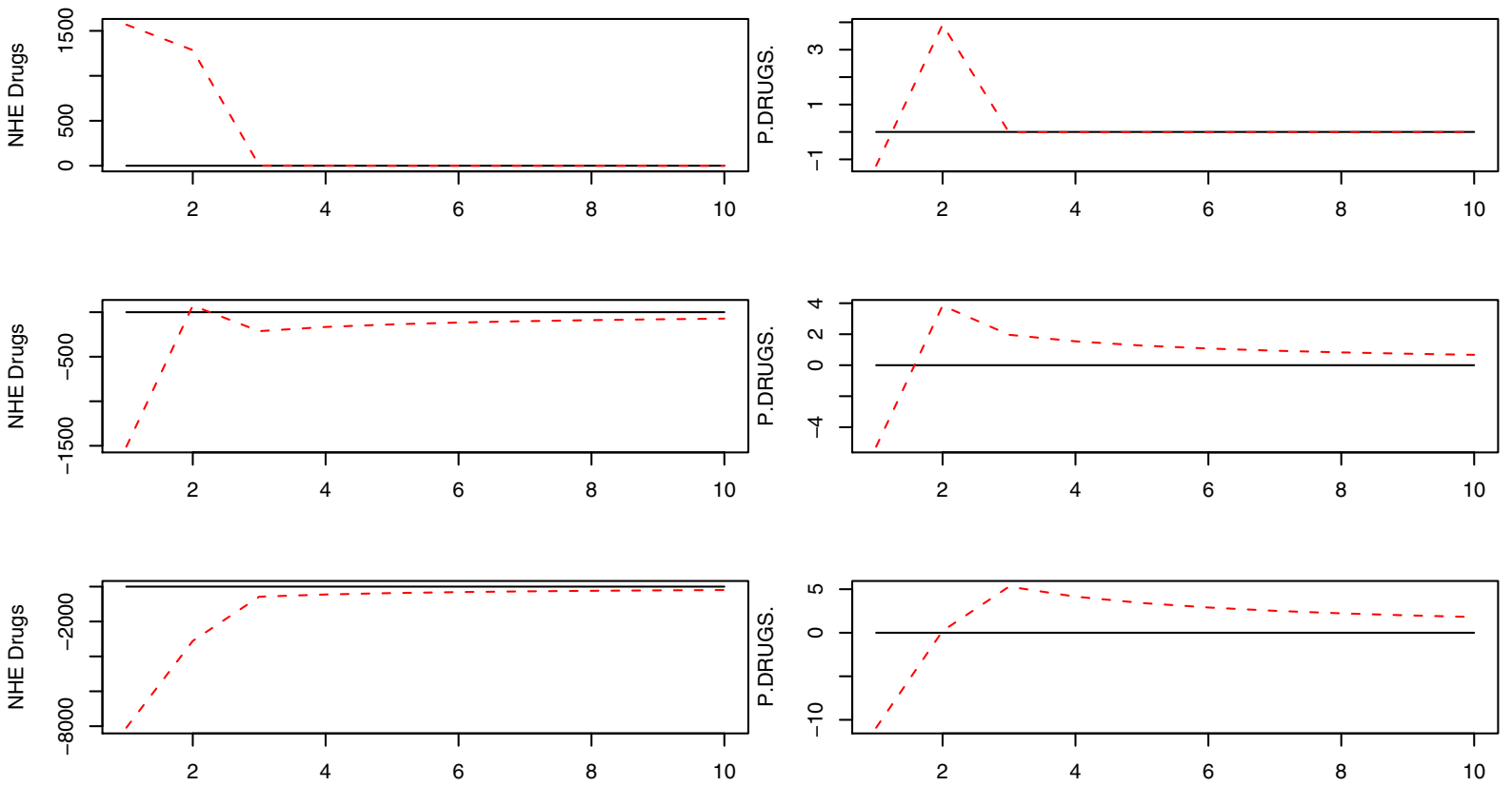

Figure 2: Pharmaceutical Market Model Impulse Response to Promotional State Variable Shocks

afford them and to provide physicians with information on drug effectiveness. And, (5) the conclusions could be greatly strengthened by extending the database into the future.

Results from state space models are strongly data dependent. Sales data may underestimate total pharmaceutical sales since data were obtained only from PhRMA members which do not include manufacturers of biologic agents. Free samples were valued at market prices which over-estimates the marginal cost to pharmaceutical manufacturers. Finally, while a decade of data is enough to estimate a state space model, it is not enough data to establish strong findings. Particularly, the effects of promotion on pharmaceutical prices will require longer time series to either confirm or reject.

The dynamics of pharmaceutical price determination continue to be an area of policy concern. Full-cost pricing (Morishima 1991, Pasdirtz 2003) argues that prices are determined by all the prices that go into producing a product or service plus a conventional markup. The basic prediction of full-cost pricing theory is that prices of inputs and outputs in an industry should all covary unless there are peculiar factors creating market failure. Prior results (Pasdirtz 2003) indicate that drug pricing has a component of variation separate from other prices. Researchers, however, have recommended against tinkering with pharmaceutical prices because it might choke off innovation (Giaccotto, Santerre, and Vernon 2005).

There have been a number of proposals to restructure the pharmaceutical industry while preserving incentives for innovation. The proposals suggest separating R\&D from drug production and marketing (Hubbard and Love 2004, Kremer 1998, Scotchmer 1999, Shavell and Ypersele 2001, Wright 1983). In these proposals, granting of marketing-monopolies through patents would be replaced by an auction/reward system where inventors were paid directly for new drugs. The compounds would then be placed in the public domain. Essentially, drugs would initially be introduced as generics. Price index theory predicts that under these proposals the aggregate price index for pharmaceuticals would decrease. Empirical work suggests large potential savings. For example, when Lorazepam went out of patent protection the expected marginal cost was about $20 \%$ of the patented product (Grabowski and Vernon 1992). This is close to other estimates suggesting that pharmaceutical prices need to be reduced by about $15 \%$ at the macro level to keep pace with growth in the US economy (Pasdirtz 2007). Since marketing and promotion decrease with patent expiration, the effect of these proposals would be to reduce the incentive for intense promotion driven by patent monopolies. 


\section{Pasdirtz}
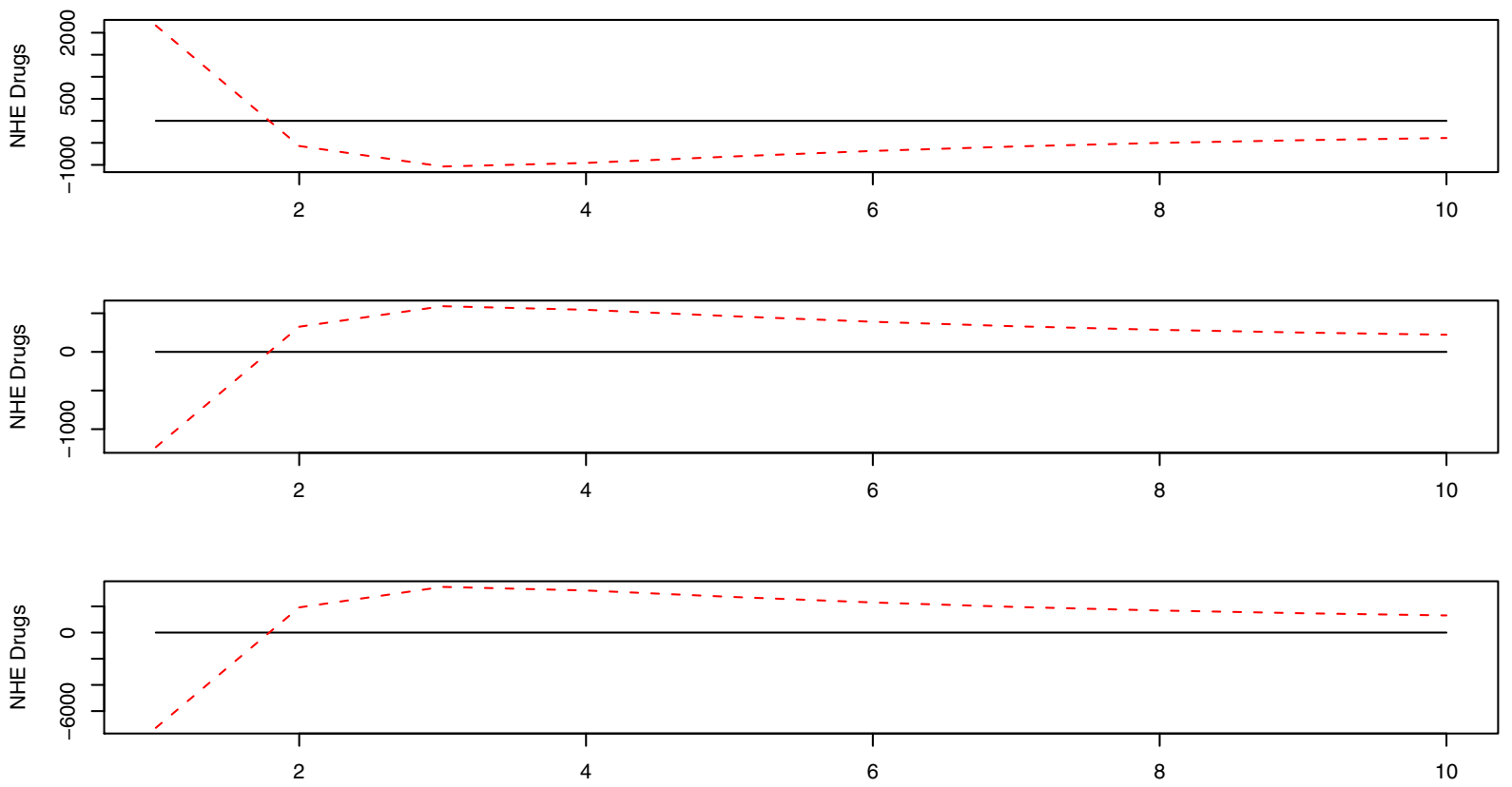

Figure 3: Impact of Promotional State Variable Shocks on Drug Expenditure

\section{ACKNOWLEDGMENTS}

I would like to thank Gordon Ridley and Tom Oliver, both at the University of Wisconsin's School of Medicine and Public Health, for suggesting the topic to me and reading early drafts of the paper. I would also like to thank James G. Anderson, Purdue University, for encouraging me to pursue macro-simulation in the health sciences. Two anonymous reviewers provided excellent feedback that improved the quality and readability of the paper. Finally, I would like to thank Julie Donohue, University of Pittsburgh, and her colleagues for creating the database and to Julie for reading an initial draft of the paper. The usual disclaimers apply.

\section{A DATA SOURCES}

Data on direct-to-consumer advertising, professional advertising (detailing and journal advertising), distribution of free samples, total promotional expenditure and total sales were taken from four sources (Donohue, Cevasco, and Rosenthal 2007): (1) DTC advertising data were obtained from TNS media which tracks local and national advertising campaigns in 44 television networks (including cable), 658 magazines, 202 newspaper, the Internet, and radio stations; (2) Advertising in medical journals was obtained from IMS Health http: //www.imshealth.com, an independent medical-information company tracking advertisements placed in approximately 400 medical journals, adding estimates of printing costs to the publishers charge for advertising; (3) Detailing was obtained from IMS Health's nationally representative panel of office-based physicians and hospital pharmacy directors who track contacts with sales representatives; (4) Distribution of free samples was obtained from a panel of approximately 1200 office staff members in medical practices, sampled from the practices of office-based physicians who are on the IMS Health detailing panel; (5) Industry-wide sales data were taken from PhRMA, (6) Data on promotional expenditures were taken from from Verispan on products in specific classes. Verispan tracks the 10 therapeutic drug classes that had the highest US sales tracking DTC advertising, detailing, advertising in professional journals, meetings and educational events for physicians and online pharmaceutical promotion to physicians. Verispan surveys 13,000 office-based and hospital-based physicians and residents, nurse practitioners, and physicians assistants who track encounters with pharmaceutical sales representatives. The panel is geographically representative and includes members of 31 clinical specialties. Verispan also produces estimates of industry expenditures on professional meetings and events through a survey of more than 3500 office-based physicians representing 19 specialties who report on events sponsored by pharmaceutical 


\section{Pasdirtz}

companies that they attend. The panel of physicians is also asked to report on online pharmaceutical-promotion activity, which includes digital (Internet and video) promotion and continuing medical education modules. Verispan audits approximately 600 medical journals and tabloids and calculates spending on the basis of each journal's rate-card information and premium-factor costs. Although these sources have limitations, I have no reason to believe that the data are biased.

The pharmaceutical Producer Price Index (PPI) was taken from the US Bureau of Labor Statistics http://www. bls.gov/pPI/ and National Health Expenditure (NHE) was taken from the Centers for Medicare \& Medicaid Services http://www.cms.hhs.gov/NationalHealthExpendData/.

\section{B Measurement Models}

For the drug promotion model, state variables were constructed from all the output variables in the system. Three state variables were constructed using principal components analysis (PCA). The first state variable captured overall growth of the system while the remaining state variables captured cyclical components. The first state variable was a relatively equal weighting of all the output variables with promotional journal advertising entering negatively. The second state variable was most heavily weighted on promotional journal advertising while the third state variable was most heavily weighted on free samples. DTC advertising covaried with other forms of promotion and was not weighted heavily on the cyclical components. The three components taken together explain $99 \%$ of the variation in the output variables. Over time, the first component grew asymptotically from 1996 to 2005. The second component reached a peak and declined after 2004. The third component showed a takeoff (increasing use of free samples and detailing) after 2003.

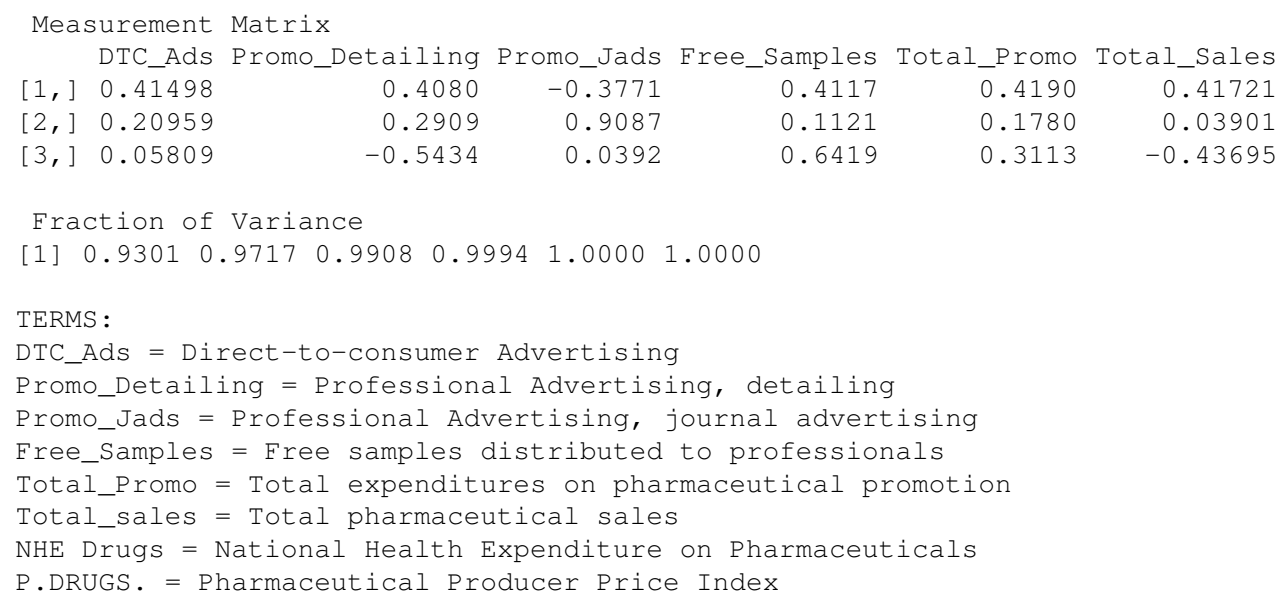

\section{Estimation}

State variables are the set of linearly independent variables that, along with input variables, describe the behavior of the system for $t \geq t_{0}$ (Rohrs, Melsa, and Schultz 1993). There are three commonly used approaches to constructing state variables that reduce the parameter space implied by the number of output variables and the lag length: (1) Aoki's method for reducing the rank of a certain Hankel data matrix (Aoki 1990), (2) Mittnik's method for reducing the rank of either the AR parameters or the Markov parameters (Mittnik 1990b, Mittnik 1990a, Mittnik 1989) and (3) computing principal components of the data matrix (Priestley, Subba, and Tong 1974, Neumaier and Schneider 2001). Each approach uses the Singular Value Decomposition (SVD). In the SDV, the state vector is constructed from either a Hankel matrix using lagged values of the output variables, the Aoki method; a Hankel matrix of the Markov parameters, the Mittnik method; or a principal components analysis (PCA) of the standardized data matrix. In this paper, each approach was tried and the best one identified using a brute force technique described below.

Evaluation of state space models is best viewed as a sequential decision process. Deciding the appropriate dimension for the state vector must balance the possibility of over-fitting against the need to construct a minimal realization. Although the fit of a model can always be improved by creating a larger state vector, at some point there will not only be diminishing returns but also a reduction in the forecasting ability of the over-fit model. The Akaike Information Criterion (AIC) provides a way to evaluate state space models with state vectors of different dimensions while correcting for over-fitting (Akaike 1974). The $A I C=2 k-2 \ln L$ where $k$ is the dimension of the parameters space and $L$ is the likelihood function. Paul Gilbert (Gilbert 1995) introduced the use of the brute-force technique (BFT) for determining the dimension of a state space model. 


\section{Pasdirtz}

The solution consists of choosing some maximum lag length, $\operatorname{trunc}\left[(n-1)^{1 / 3}\right]$, where $n$ is the number of periods in the output data vector, and estimating the model at each lag length up to the maximum. The best model was selected using the AIC. Here, I extend the BFT approach to include not only the state space dimension but also the evaluation of the model specification and the method used to construct the state vectors. The BFT algorithm can easily be programmed on a digital computer to test all the possibilities and return the best model based on the minimum AIC. All the algorithms were implemented in the statistical computing language $\mathrm{R}$ ( $\mathrm{R}$ Development Core Team 2006). PCA models won all the BFT competitions.

\section{REFERENCES}

Adams, C. P., and V. V. Brantner. 2006, March. Estimating the cost of new drug development: Is it really $\$ 802$ million? Health Affairs 25 (2): 420-428.

Akaike, H. 1974, December. Stochastic Theory of Minimal Realization. IEEE Transactions on Automatic Control 19:667-674.

Anderson, G. F., U. E. Reinhardt, P. S. Hussey, and V. Petrosyan. 2003. It's the Prices Stupid: Why the United States Is So Different From Other Countries. Health Affairs 23 (3): 89-105.

Annonymous 2008, March. Managing Physician and Pharmaceutical Industry Interactions: Exemplary Policies. The best conflict of interest policies at academic medical centers subject by subject, Center on Medicine as a Profession, Columbia University, New York, NY, USA.

Aoki, M. 1990. State Space Modeling of Time Series. New York, NY: Springer-Verlag.

Berndt, E. R. 2002. Pharmaceuticals in U.S. Health Care: Determinants of Quantity and Price. The Journal of Economic Perspectives 16 (4): 45-66.

Blanchard, O. J., and D. Quah. 1989, September. The Dynamic Effects of Aggregate Demand and Supply Disturbances. The American Economic Review 79 (4): 655-673.

Blanchard, O. J., and D. Quah. 1993. The dynamic effects of aggregate demand and supply disturbances: Reply. The American Economic Review 83 (3): 653-658.

Clements, M. P., and N. Taylor. 2001. Bootstrapping prediction intervals for autoregressive models. International Journal of Forecasting 17 (2): 247-267.

Cooley, T. F., and S. F. Leroy. 1985. Atheoretical macroeconometrics: A critique. Journal of Monetary Economics 16 (3): 283-308.

Demasi, J. A., R. W. Hansen, and H. G. Grabowski. 2003. The price of innovation: new estimates of drug development costs. Journal of Health Economics 22:151-185.

Diewert, W. E. 1993. Index Numbers. In Essays in Index Number Theory, ed. W. E. Diewert and A. O. Nakamura, Chapter 5, 71-108. Amsterdam, Netherlands: Elsevier Science Publishers.

Donohue, J. M. 2006. Direct-to-Consumer Advertising of Prescription Drugs: Adding to overuse and inappropriate use or alleviating underuse? International Journal of Pharmaceutical Medicine 20 (1): 17-24.

Donohue, J. M., M. Cevasco, and M. B. Rosenthal. 2007, August. A Decade of Direct-to-Consumer Advertising of Prescription Drugs. New England Journal of Medicine 357:673-681.

Dorfman, R., and P. O. Steiner. 1954. Optimal advertising and optimal quality. The American Economic Review 44 (5): 826-836.

Frank, R. G., and D. S. Salkever. 1992. Pricing, patent loss and the market for pharmaceuticals. Southern Economic Journal 59 (2): $165-179$.

Freedman, D. A. 1981, November. Bootstrapping Regression Models. Annals of Statistics 9:1218-1228.

Freedman, D. A., and S. C. Peters. 1984, March. Bootstrapping a Regression Equation: Some Empirical Results. Journal of the American Statistical Association 79:97-106.

GAO 2002, October. Prescription Drugs: FDA Oversight of Direct-to-Consumer Advertising Has Limitations. Report to Congressional Requesters, Government Accountability Office, Washington, D.C.

Giaccotto, C., R. E. Santerre, and J. A. Vernon. 2005. Drug prices and research and development investment behavior in the pharmaceutical industry. The Journal of Law and Economics 48 (1): 195-214.

Gilbert, P. D. 1995. Combining VAR Estimation and State Space Model Reduction for Simple Good Predictions. Journal of Forecasting: Special Issue on VAR Modeling 14:229-250.

Gönül, F. F., F. Carter, E. Petrova, and K. Srinivasan. 2001. Promotion of Prescription Drugs and Its Impact on Physicians' Choice Behavior. The Journal of Marketing 65 (3): 79-90.

Grabowski, H., and J. Vernon. 2000. The determinants of pharmaceutical research and development expenditures. Journal of Evolutionary Economics 10:201-215. 


\section{Pasdirtz}

Grabowski, H. G., and J. M. Vernon. 1992. Brand loyalty, entry, and price competition in pharmaceuticals after the 1984 drug act. Journal of Law and Economics 35 (2): 331-350.

Granger, C. W. J. 1969, August. Investigating Causal Relations by Econometric Models and Cross-spectral Methods. Econometrica 37 (3): 424-438.

Hartley, J. E. 1996. Retrospectives: The origins of the representative agent. The Journal of Economic Perspectives 10 (2): $169-177$.

Hubbard, T., and J. Love. 2004, February 17. A New Trade Framework for Global Healthcare R\&D. PLoS Biol 2 (2): e52-.

IOM 2009, April. Conflict of Interest in Medical Research, Education, and Practice. Report Brief, Institute of Medicine, Washington, D.C.

Kalman, R. E. 1980, March. System-theoretic critique of dynamic economic models. International Journal of Policy Analysis and Information Systems 4 (1): 3-22.

Kirman, A. P. 1992. Whom or what does the representative individual represent? The Journal of Economic Perspectives 6 (2): 117-136.

Kremer, M. 1998. Patent buyouts: A mechanism for encouraging innovation. The Quarterly Journal of Economics 113 (4): $1137-1167$.

Lewis, C. 2003, March-April. The Impact of Direct-to-Consumer Advertising. FDA Consumer Magazine:1-2.

Lim, C., and N. P. Ong. 1989. A dynamic model of advertising and market shares. The Canadian Journal of Economics / Revue canadienne d'Economique 22 (4): 819-833.

Lutkepohl, H. 2006. New Introduction to Multiple Time Series Analysis. New York, NY: Springer.

Mittnik, S. 1989. Multivariate Time Series Analysis With State Space Models. Computers and Mathematics with Applications 17:1189-1201.

Mittnik, S. 1990a. Forecasting With Balanced State Space Representations of Multivariate Distributed Lag Models. Journal of Forecasting 9:207-218.

Mittnik, S. 1990b. Macroeconomic forecasting experience with balanced state space models. International Journal of Forecasting 6:337-348.

Moore, E. J. 1985, February. On system-theoretic methods and econometric modeling. International Economic Review 26 (1): $655-673$.

Morishima, M. 1991, January. General Equilibrium Theory in the Twenty-First Century. The Economic Journal 101 (404): 69-74.

Morrison, D. F. 1967. Multivariate Statistical Methods. New York, NY: McGraw-Hill.

Nerlove, M., and K. J. Arrow. 1962. Optimal advertising policy under dynamic conditions. Economica 29 (114): 129-142.

Neumaier, A., and T. Schneider. 2001. Estimation of parameters and eigenmodes of multivariate autoregressive models. ACM Transactions on Mathematical Software 27:27-57.

Pasdirtz, G. W. 2003. A State Space Dynamic Modes Model of Health Care Prices, 1900-1950. In Proceedings of the 2003 International Conference on Health Sciences Simulation, ed. J. G. Anderson and M. Katzper, 3-8. San Diego, CA: SCS: The Society for Modeling and Simulation International.

Pasdirtz, G. W. 2007, http://dx.doi.org/10.1007/s10729-007-9028-5. Controlling the US health care system with policy wedges. Health Care Management Science 10 (4): 311-329.

Priestley, M. B., T. Subba, and H. Tong. 1974, December. Applications of Principal Component Analysis and Factor Analysis in the Identification of Multivariable Systems. IEEE Transactions on Automatic Control 19:730-734.

R Development Core Team 2006. R: A language and environment for statistical computing. Technical Report http: //www.R-project.org/, R Foundation for Statistical Computing, Vienna, Austria.

Rizzo, J. A. 1999, April. Advertising and competition in the ethical pharmaceutical industry: The case of antihypertensive drugs. Journal of Law \& Economics 42 (1): 89-116.

Robinson, J. C. 1999. The Corporate Practice of Medicine. Berkeley, CA: University of California Press.

Rohrs, C. E., J. L. Melsa, and D. G. Schultz. 1993. Linear control systems. New York, NY: McGraw-Hill.

Rozenblit, J. W., and B. P. Zeigler. 1993. Representing and constructing system specifications using the system entity structure concepts. In WSC '93: Proceedings of the 25th conference on Winter simulation, 604-611. New York, NY, USA: WSC: ACM.

Runkle, D. E. Oct., 1987. Vector autoregressions and reality. Journal of Business \& Economic Statistics 5 (4): 437-442.

Scotchmer, S. 1999, Summer. On the optimality of the patent renewal system. RAND Journal of Economics 30 (2): 181-196.

Shavell, S., and T. V. Ypersele. 2001. Rewards versus Intellectual Property Rights. Journal of Law and Economics 44 (2): $525-547$. 


\section{Pasdirtz}

Sims, C. 1986, Winter. Are Forecasting Models Usable for Policy Analysis? Federal Reserve Bank of Minneapolis Quarterly Review:2-15.

Stoffer, D. S., and K. D. Wall. 1991, December. Bootstrapping State-Space Models: Gaussian Maximum Likelihood Estimation and the Kalman Filter. Journal of the American Statistical Association 86:1024-1033.

Stoll, R. J. 1982, February. Let the Researcher Beware: The Use of the Richardson Equations to Estimate the Parameters of a Dyadic Arms Acquisition Process. American Journal of Political Science 26:77-89.

Sweet, D. 2005, September. Statement of the American College of Physicians to the Senate Special Committee on Aging: The Hearing on the Impact of Direct-to-Consumer Advertising on Seniors' Health and Health Care Costs. Testimony, United States Senate, Washington, D.C.

Triplett, J. E. 1992, April. Economic Theory and BEA's Alternative Quantity and Price indices. Survey of Current Business:4952.

Wright, B. D. 1983. The economics of invention incentives: Patents, prizes, and research contracts. The American Economic Review 73 (4): 691-707.

Zeigler, B. P., and S. Vahie. 1993. DEVS formalism and methodology: unity of conception/diversity of application. In Proceedings of the 1993 Winter Simulation Conference, 573-579. New York, NY, USA: Institute of Electrical and Electronics Engineers, Inc.

\section{AUTHOR BIOGRAPHY}

GEORGE W. PASDIRTZ is retired from the University of Wisconsin. His interest in health care developed after working for Corning Pharmaceuticals during the early 1990's. He has taught statistics and computer science and also chaired the University's subcommittee for technical implementation of HIPAA. He can be contacted at mailto:pasdirtz@wisc.edu. 